\title{
Phosphodiestrase 5 and effects of sildenafil on cerebral arteries from man and guinea pig
}

\author{
Christina Kruuse *1,2, Tejvir S Khurana1,3,4, Sergei D Rybalkin ${ }^{5}$, Steffen Birk², \\ Ulla Engel ${ }^{6}$, Lars Edvinsson ${ }^{1,7}$ and Jes Olesen ${ }^{2}$
}

\begin{abstract}
Address: ${ }^{1}$ Department of Clinical Experimental Research, Glostrup Hospital, University of Copenhagen, Glostrup, Denmark, ${ }^{2}$ Danish Headache Center and Department of Neurology, Glostrup Hospital, University of Copenhagen, Glostrup, Denmark, ${ }^{3}$ Department of Clinical Biochemistry, Glostrup Hospital, University of Copenhagen, Glostrup, Denmark, ${ }^{4}$ Department of Physiology \& Pennsylvania Muscle Institute, University of Pennsylvania, Philadelphia, USA, ${ }^{5}$ Dept. of Pharmacology, University of Washington, Seattle, USA, ${ }^{6}$ Department of Pathology, Hillerod Hospital, Hillerod, Denmark and ${ }^{7}$ Division of Experimental Vascular Research, Department of Internal Medicine, University Hospital of Lund, Lund, Sweden

Email: Christina Kruuse* - ckruuse@dadlnet.dk

* Corresponding author
\end{abstract}

from 2nd International Conference of cGMP Generators, Effectors and Therapeutic Implications Potsdam, Germany, 10-12 June, 2005

Published: 16 June 2005

BMC Pharmacology 2005, 5(SuppI I):P28 doi:I0.I I86/I47I-22 I0-5-SI-P28

\section{Background}

The specific inhibitor of the cGMP degrading enzyme phosphodiesterase 5 (PDE5), sildenafil (Viagra ${ }^{\circledR}$ ), induces migraine without significant cerebral artery dilatation in vivo. This is in contrast to other migraine inducing substances such as glyceryl trinitrate and histamine which are effective vasodilators. Sildenafil is also recently found to enhance functional recovery, neurogenesis and angiogenesis in stroke models. We evaluated the presence of PDE5 and functional effects of three selective PDE inhibitors in human and guinea pig cerebral arteries.

\section{Materials and methods}

RT-PCR and Western blot were used to establish the presence of PDE5 mRNA and protein respectively. The effects of sildenafil, UK-114,542 (both PDE5 specific) and UK90,234 (PDE1 specific) on cyclic nucleotide hydrolysis were investigated using homogenates of human and guinea pig cerebral arteries. In isolated guinea pig basilar arteries the cerebral vasodilator responses of the PDE inhibitors were investigated. Concomitantly the tissue levels of cAMP and cGMP were analysed.

\section{Results}

PDE5A mRNA and protein were present in human middle cerebral artery. Sildenafil and UK-114,542 caused a concentration-dependent inhibition of cGMP hydrolysis. Sildenafil induced an endothelium dependent vasodilatation ( $\mathrm{pEC}_{50} 6.0 \pm 0.3$ ), which was less than $10 \%$ of maxi- mal dilatation within the clinically effective plasma concentrations after oral sildenafil $100 \mathrm{mg}$ ( $40 \mathrm{nM}$ ) (See figure 1). The dilatation was augmented by sodium nitroprusside (SNP) pre-treatment. UK-114,542 $\left(\mathrm{pEC}_{50} 8.6 \pm\right.$ 0.1 ) was a more potent vasodilator than sildenafil. The PDE1 inhibitor UK-90,234 elicited a non-specific response with poor potency $\left(\mathrm{pEC}_{50} 5.2 \pm 0.1\right)$. The

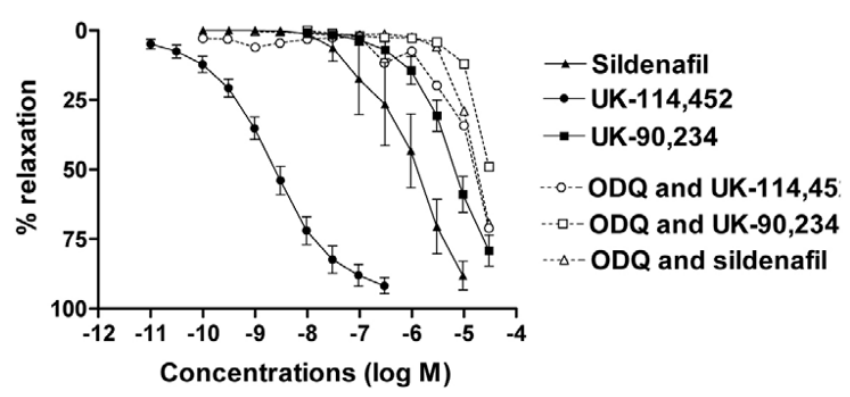

Figure I

Concentration-response curve for UK-90,234 (square), UKI I4,542 (circle) and sildenafil (triangle) without (filled symbols) and with (open symbols) pre-treatment with the inhibitor of soluble guanylate cyclase, ODQ $(10 \mu \mathrm{M})$, in intact arteries. Relaxation is given as \% relaxation of pre-contraction and each point shows mean \pm S.E.M. In high concentrations all compounds elicited a small cGMP-independent dilatory response. 
vasodilatation was attenuated by endothelial removal or pharmacological inhibition of endogenous cGMP production, but a cGMP-independent dilatory response was seen at high concentrations.

\section{Conclusion}

Sildenafil in vitro mainly dilates cerebral arteries above relevant plasma concentrations of sildenafil, unless a nitric oxide donor is co-administered. These results supports the lack of vascular response previously found in human in vivo studies and may suggest a possible neuronal rather than vascular effect of sildenafil in migraine induction.

Publish with Bio Med Central and every scientist can read your work free of charge

"BioMed Central will be the most significant development for disseminating the results of biomedical research in our lifetime. " Sir Paul Nurse, Cancer Research UK

Your research papers will be:

- available free of charge to the entire biomedical community

- peer reviewed and published immediately upon acceptance

- cited in PubMed and archived on PubMed Central

- yours - you keep the copyright

Submit your manuscript here:

http://www.biomedcentral.com/info/publishing_adv.asp 